\title{
Three-dimensional velocity structure in the source region of the Noto Hanto Earthquake in 2007 imaged by a dense seismic observation
}

\author{
Aitaro Kato ${ }^{1}$, Shinichi Sakai ${ }^{1}$, Takashi Iidaka ${ }^{1}$, Takaya Iwasaki $^{1}$, Eiji Kurashimo ${ }^{1}$, Toshihiro Igarashi ${ }^{1}$, Naoshi Hirata ${ }^{1}$, \\ Toshihiko Kanazawa ${ }^{1}$, and Group for the aftershock observations of the 2007 Noto Hanto Earthquake \\ ${ }^{1}$ Earthquake Research Institute, University of Tokyo, Tokyo, Japan
}

(Received June 30, 2007; Revised October 12, 2007; Accepted October 15, 2007; Online published February 19, 2008)

\begin{abstract}
The velocity structure and accurate aftershock distributions of the Noto Hanto Earthquake in 2007 (thrust type) are elucidated by inverting the arrival times from 917 aftershocks using double-difference tomography. $P$-wave velocity $\left(V_{p}\right)$ of the hanging wall in the southeast appears to be higher than that of the footwall in the northwest, and the high- $V_{p}$ body of the hanging wall has a relatively high $V_{p} / V_{s}$ ratio. Conversely, the low- $V_{p}$ body in the footwall appears to have a low $V_{p} / V_{s}$ ratio at depths greater than $3 \mathrm{~km}$. Aftershocks associated with the mainshock fault are roughly distributed along this velocity boundary between the hanging wall and footwall. Near-surface thin layers with significantly low $V_{p}$ and high $V_{p} / V_{s}$ are imaged in a northwest direction from the mainshock epicenter. A likely explanation is that the mainshock fault plane was reactivated as a reverse fault in terms of the inversion tectonics due to the crustal shortening which initiated from the late Miocene. Both the mainshock hypocenter and the vertical alignment of aftershocks beneath it are located in the low- $V_{p}$ and low$V_{p} / V_{s}$ zones, indicating the potential presence of water-filled pores. Crustal stretching and shortening in and around the Noto Peninsula have created complex structures, including weak high-dip angle faults, almost vertical faults, and low velocity zones, which can potentially affect the seismic activities around the source region.
\end{abstract}

Key words: Tomography, the Noto Hanto Earthquake in 2007, aftershocks, inversion tectonics.

\section{Introduction}

A shallow $M_{\mathrm{w}}=6.7$ inland earthquake occurred on the west coast of the Noto Peninsula in Japan on March 25, 2007, inflicting serious damage in the surrounding areas. Aftershocks were distributed at the boundary between the area inland and the ocean to the west of the Peninsula. A tsunami with a small amplitude (approximately $20 \mathrm{~cm}$ ) was observed at several cities along the coast of the Japan Sea. The focal mechanism estimated by moment tensor inversion (the National Research Institute for Earth Science and Disaster Prevention (NIED)) was found to have a dominant reverse slip component with a strike of approximately N55E (Fig. 1). The dip angle of the mainshock fault is approximately $60^{\circ}$. This high-dip angle for a thrust-type event is unfavorably oriented in the direction of the regional maximum stress, which is almost horizontal to the west-northwest (WNW)-east-southeast (ESE) strike (Townend and Zoback, 2006). Two of the largest aftershocks occurred on the northeastern and southwestern edges of the mainshock fault.

The Noto Peninsula is situated close to the Yamato Basin in the Japan Sea, which is a large rift basin formed during the extension stage of the Japan Sea (e.g., Otofuji et al., 1985; Shimazu et al., 1990). Based on geological studies of early Miocene syn-rifting succession in the northern regions of the Noto Peninsula (e.g., Kano et al., 2002), it has been

Copyright (c) The Society of Geomagnetism and Earth, Planetary and Space Sciences (SGEPSS); The Seismological Society of Japan; The Volcanological Society of Japan; The Geodetic Society of Japan; The Japanese Society for Planetary Sciences; TERRAPUB. proposed that small-scale rift structures were formed along the northern coast of the Noto Peninsula during the extension stage of the Japan Sea. The normal fault system in the rift structures has subsequently reactivated as a reverse fault system owing to the development of a compressional stress field (Okamura et al., 1995). While the direction of the maximum compressional stress was north-south during the late Miocene, it has changed to east-west (EW) since late Pliocene (e.g., Okamura, 2007), and numerous faults with north-south (NS) or EW trends have developed in the source region. Since the complex structures associated with crustal stretching and uplifting during the opening of the Japan Sea have the potential to nucleate the mainshock and trigger a sequence of aftershocks (e.g., Hirata et al., 2005; Kato et al., 2006), it is important to image the complex seismogenic structures surrounding the source region and clarify their relationship to the rupture process (e.g., Chiarabba and Amato, 2003).

While online seismic networks have been operated on the Noto Peninsula by the NIED, Japan Meteorological Agency (JMA), universities, and the Japanese University Group of the Joint Seismic Observations at NKTZ (Niigata-Kobe Tectonic Zone) (2005), the average spacing of these stations is not sufficient for resolving the detailed velocity structure in the source region with high accuracy. Therefore, in order to be able to accurately assess the velocity structure in and around the source region in the study reported here, we employ the distinctive aftershock data observed by a dense network of temporary seismic stations that were deployed by the group responsible for the aftershock observations im- 


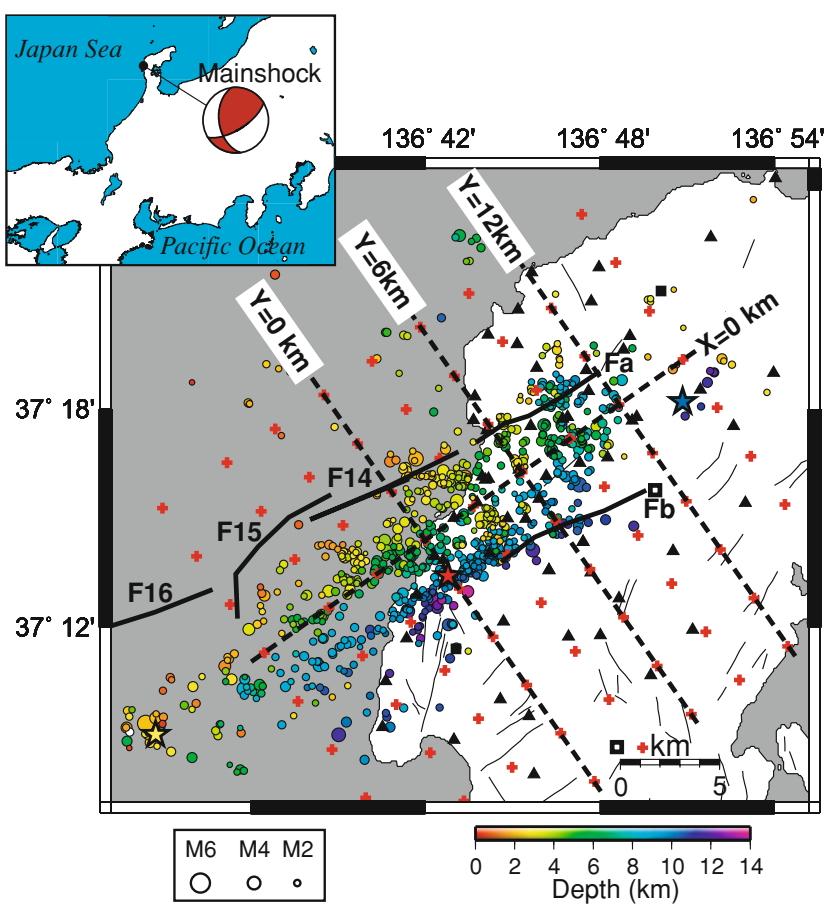

Fig. 1. Map of the relocated aftershock hypocenters determined by double-difference tomography, shown as circles scaled to earthquake magnitude and colored to depth. The red star denotes the epicenter of mainshock, the blue and yellow stars are epicenters of largest aftershocks on land and beneath the ocean. The inset indicates the location of the area studied in investigation with moment tensor for the mainshock determined by NIED. Filled triangles and squares denote temporary seismic stations, and online stations, respectively. Open squares are temporary online stations operated by the Japanese University Group of the Joint Seismic Observations at NKTZ (2005). The grid used in the tomography is shown by red crosses. Active- $(F 14-F 16)$ and geological-faults $\left(F_{a}, F_{b}\right)$ associated with the present earthquake are drawn as thick solid lines, and the other major active faults are drawn as thin solid lines.

mediately after the Noto Hanto Earthquake in 2007 (Sakai et al., 2008). A total of 61 temporary seismic stations in the source region were employed in this study (average station spacing is $2 \mathrm{~km}$ ). Here, we report on our study of the seismic tomography in and around the source region using this data set and discuss the relationship between heterogeneous velocity structures and the earthquake generation process.

\section{Velocity Structure on the Mainshock Fault \\ 2.1 Data and method}

The seismic network in the present study consisted of 61 three-component temporary stations, 13 permanent online stations (NIED, JMA, Kyoto University, University of Tokyo), and five temporary online stations operated by the Japanese University Group of the Joint Seismic Observations at NKTZ (2005). Those stations are located within a radius of $70 \mathrm{~km}$ from the center of the source region (Fig. 1). Seismograms were continuously recorded at a sampling rate of $100 \mathrm{~Hz}$ or $200 \mathrm{~Hz}$. Both $P$ - and $S$ wave arrival times observed at the temporary and online stations were picked manually. The double-difference tomography method (Zhang and Thurber, 2003) was then applied to arrival time data, which consisted of both absolute and differential arrival times. The differential arrival times were derived from both manually picked data and the
Table 1. List of the initial velocity model for the tomography.

\begin{tabular}{cc}
\hline Depth $(\mathrm{km})$ & $V_{p}(\mathrm{~km} / \mathrm{s})$ \\
\hline 0 & 5.40 \\
3 & 6.00 \\
6 & 6.15 \\
9 & 6.19 \\
12 & 6.22 \\
15 & 6.27 \\
\hline
\end{tabular}

waveform cross-correlation method. This method simultaneously solves for the three-dimensional velocity structure of both $P$ - and $S$-wave velocities $\left(V_{p}, V_{s}\right)$ and seismic event locations.

In this study, we used 971 well-determined aftershocks estimated from sufficient arrival time data; the number of $P$ - and $S$-wave arrival times for each event exceeded 15 and 10, respectively. The aftershocks are listed in the JMA catalog for the period between March 25 and April 18.

The initial 971 hypocenter locations used for tomography analysis were determined by applying a maximum likelihood estimation algorithm (Hirata and Matsu'ura, 1987) to the observed arrival times, for a one-dimensional (1-D) velocity structure, as presented by Mikumo et al. (1988) (Table 1). The initial velocity structure used for tomographic analysis is the same as that employed for the hypocenter determinations; the $V_{p} / V_{s}$ value is set to 1.73 for all grid nodes. The absolute arrival times for the $P$ - and $S$ wave used in the tomography are 44,278 and 36,758 , respectively, with the differential arrival times for the manually picked $P$ - and $S$-waves reaching 232,063 and 172,401 , respectively. We also used the differential arrival times obtained by the waveform cross-correlation method in the time-domain (Schaff et al., 2004; Kato et al., 2006). The correlation measurements were conducted by aligning the nearest sample using 1.0-s window lengths beginning $0.4 \mathrm{~s}$ before the manually picked arrival time and then computing the double difference time to subsample precision using time-domain cross-correlation. We were left with a data set consisting of more accurate differential arrival times that contained 22,897 $P$-wave and 25,122 $S$-wave observations, respectively. These have a normalized cross-correlation coefficient exceeding 0.85 .

The grid nodes are located at $-300,-29,-9,-6,-3$, $-0,3,6,9,12,15,35$, and $300 \mathrm{~km}$ on the $X$-axis $(\mathrm{N} 145 \mathrm{E}$; perpendicular to the fault strike); $-300,-30,-10,-6,-3$, $-0,3,6,9,12,16,36$, and $300 \mathrm{~km}$ on the $Y$-axis (N55E); $-150,0,3,6,9,12,15,20$, and $300 \mathrm{~km}$ on the $Z$-axis (depth) (Fig. 1). The weighted root mean square (RMS) travel time residual was reduced from $0.154 \mathrm{~s}$ to $0.033 \mathrm{~s}$ after 16 iterations.

\subsection{Results}

We evaluated the model resolution using the following synthetic test. A checkerboard velocity model on the mainshock fault plane was created from the initial velocity structure using perturbations of $\pm 5 \%$. Synthetic travel times were then calculated for this checkerboard model, with uniformly distributed random noises ranging from $-0.025 \mathrm{~s}$ to $0.025 \mathrm{~s}$ for the $P$-wave and from $-0.05 \mathrm{~s}$ to $0.05 \mathrm{~s}$ for 
the $S$-wave. The synthetic data were subsequently inverted using the initial velocity structure as a starting model. We defined a good recovery grid as a grid for which the recovery of the initial anomaly was greater than $20 \%$ for $V_{p}$ or $V_{s}$ of the assumed model velocity. Although $P$-wave or $S$-wave velocity anomalies were well recovered at land cross-sections $(Y>0 \mathrm{~km})$, model resolutions beneath the ocean were relatively low due to the absence of any seismic stations in the ocean. Consequently, the interpretations presented in this paper will focus mainly on the velocity structures at land cross-sections from $Y=-3 \mathrm{~km}$ to $+16 \mathrm{~km}$. In future studies, model resolutions beneath the ocean will be improved through an integration of data retrieved from ocean bottom seismometers deployed off the west coast of the Noto Peninsula (Yamada et al., 2007).

Figure 2 shows the $P$-wave velocity $\left(V_{p}\right)$ and the ratio of $V_{p}$ to $V_{s}$ along seven cross-sections perpendicular to the fault strike along relocated aftershocks within $\pm 1.5 \mathrm{~km}$ from the section. Based on the aftershock distributions, it has been estimated that the mainshock occurred on the approximately $55^{\circ}$ southeastward-dipping plane. Surface extension of the mainshock fault roughly corresponds to the surface traces of several active faults beneath the ocean (F 14-F 16) and a geological fault (defined as a fault for which activity history has not been recognized since the Quaternary period), $F_{a}$ (Katagawa et al., 2005; GSJ, 2005).

Note that $P$-wave velocities of the hanging wall in the SE appear to be higher than those of the footwall in the NW. Figure 2 shows that the high- $V_{p}$ body of the hanging wall has a slightly high $V_{p} / V_{s}$ ratio $(1.75 \sim 1.8)$, while the low- $V_{p}$ body in the footwall appears to have a low $V_{p} / V_{s}$ ratio $(1.6 \sim 1.7)$ at depths greater than $3 \mathrm{~km}$ in the crosssections shown in Figs. 2(j) and 2(k). While the contrast in velocity between the hanging wall and footwall are not distinct in several cross-sections, this is probably due to the effect of spatial smoothing adopted in the inversion. Note that the aftershocks associated with the mainshock fault are distributed approximately along this southeastward-dipping velocity boundary. Furthermore, near-surface thin layers with significantly low $V_{p}$ (less than $5.0 \mathrm{~km} / \mathrm{s}$ ) and high $V_{p} / V_{s}(>1.9)$ were imaged northwestward of the mainshock epicenter $(X<\sim 0 \mathrm{~km})$.

It is interesting that the dip angle of the aftershock alignment changes markedly from $55^{\circ}$ to nearly $90^{\circ}$ beneath the mainshock hypocenter in the cross-section of $Y=0 \mathrm{~km}$ (Fig. 2). The epicenter distributions of these aftershocks beneath the mainshock hypocenter were linearly concentrated along the fault strike of N55E (Fig. 1), and the size of the vertical aftershock alignment was approximately $3 \mathrm{~km} \times$ $3 \mathrm{~km}$. Interestingly, $P$-wave velocities beneath the mainshock hypocenter and near the vertical aftershock alignment were lower than those in the surroundings.

Portions of the high- $V_{p}$ body in the hanging wall were observed to extend upward to the surface where $X$ is approximately $+3 \mathrm{~km}$ in the cross-sections of $Y=+3$ and $+6 \mathrm{~km}$. The top surface of the high- $V_{p}$ body in the hanging wall gradually deepens toward the NW at $0<X<3 \mathrm{~km}$ in these sections. Thus, another velocity boundary, dipping northwestward, is situated at shallow depths of the high- $V_{p}$ body. Note that northwestward-dipping alignment of after-
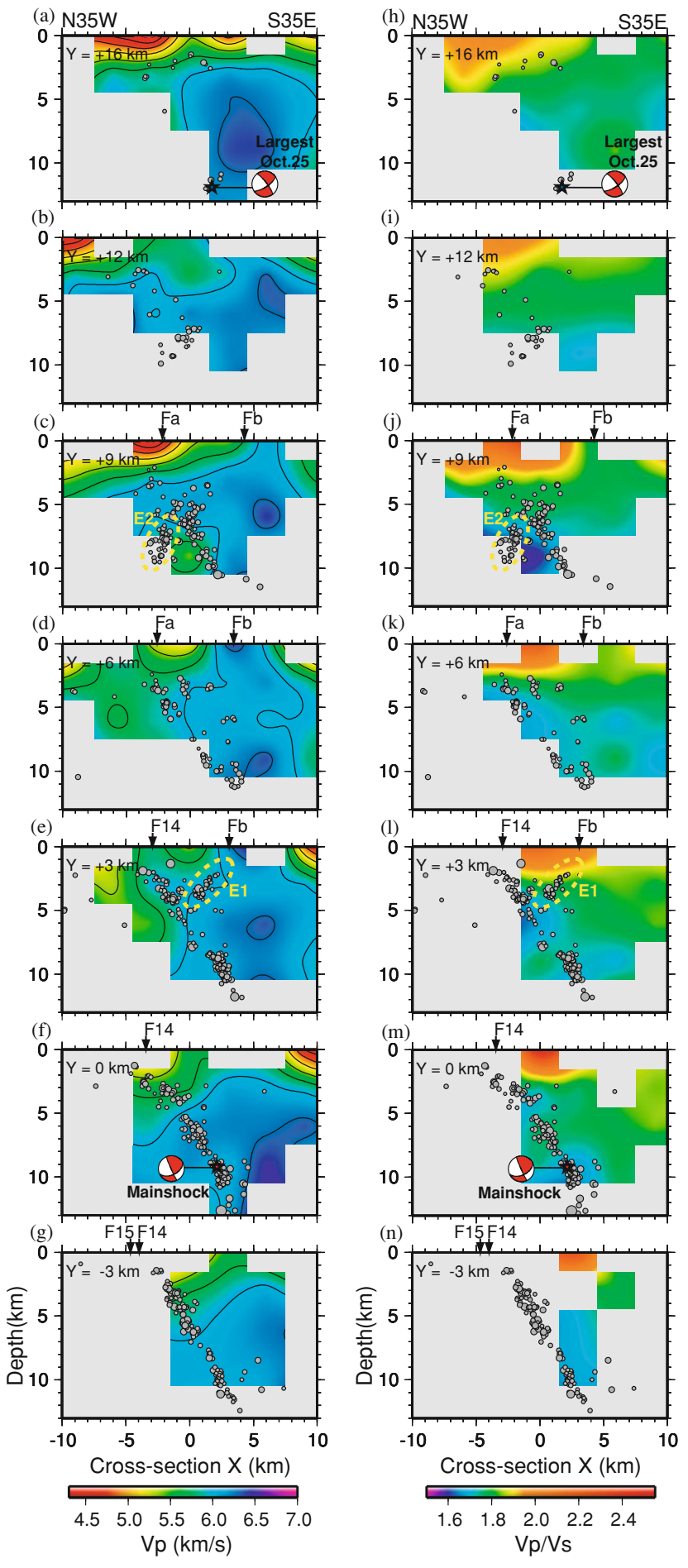

Fig. 2. Depth sections through the $V_{p}((\mathrm{a})-(\mathrm{g}))$ and $V_{p} / V_{s}$ ratio model ((h)-(n)) with superimposed relocated aftershocks distributed within $\pm 1.5 \mathrm{~km}$ of each line. Depth sections are ordered from NE to SW. The white-masked areas correspond to the low-resolution model. The contour line interval is $0.3 \mathrm{~km} / \mathrm{s}$. Yellow dashed ellipses (E1, E2) are explained in text. Moment tensor solutions for the mainshock and the largest aftershock (NIED) are shown using a lower hemisphere projection. Arrows at the top of each section denote the approximate surface locations of faults.

shocks with an angle of $50^{\circ}$ (E1 in Fig. 2) is approximately distributed on the shallow velocity boundary. The surface extension of this northwestward-dipping velocity boundary almost coincides with a geological fault $F_{b}$. 


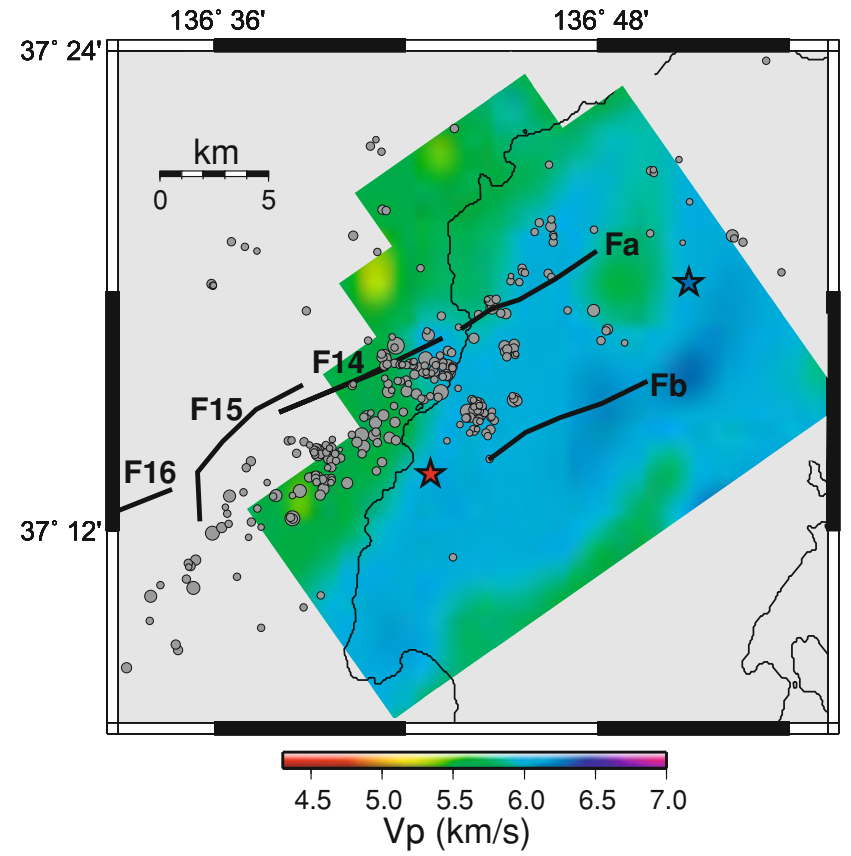

Fig. 3. Map view of $V_{p}$ structure at a depth of $3 \mathrm{~km}$ with superimposed relocated aftershocks distributed at depths from $1.5 \mathrm{~km}$ to $4.5 \mathrm{~km}$. The faults $\left(F 14-F 16, F_{a}, F_{b}\right)$ associated with the present earthquake are drawn as thick lines. Red and blue stars denote the epicenters of the mainshock and the largest aftershock.

Figure 3 shows a map of the $V_{p}$ structure at a depth of $3 \mathrm{~km}$. It can be observed that the distribution of the high- $V_{p}$ body in the hanging wall is confined to a zone that is parallel to the NE-SW direction at the depth of $3 \mathrm{~km}$. Furthermore, surface traces of geological faults $\left(F_{a}, F_{b}\right)$ are situated in close proximity to velocity boundaries at the depth of $3 \mathrm{~km}$. In short, $V_{p}$ at the NW side of $F_{a}$ is less than that at the SE side of $F_{b}$, with the $V_{p}$ between $F_{a}$ and $F_{b}$ showing an intermediate value.

On the cross-section of $Y=+9 \mathrm{~km}$, northwestwarddipping alignments of aftershocks are also observed at depths near $8 \mathrm{~km}$ (E2 in Fig. 2). They appear to be distributed along a minor velocity boundary in the footwall.

\section{Discussion}

Figure 2 shows that the aftershock alignments associated with the mainshock extend to the surface traces of several active faults beneath the ocean $(F 14-F 16)$ and the geological fault $\left(F_{a}\right)$. The results of previous shallow seismic reflection experiments indicate that the active faults beneath the ocean dip southeastward (Katagawa et al., 2005; GSJ, 2005). In addition, a magnetic survey on land has shown that the geological fault $\left(F_{a}\right)$ may correspond to a material boundary dipping southeastward (Ogawa et al., personal communication). Based on these observations, we propose that the rupture of the Noto Hanto Earthquake was likely to have propagated along these preexisting faults.

The seismic images obtained in this study illustrate that the contrast in velocity between the hanging wall and the footwall extends to a depth of approximately $10 \mathrm{~km}$, as summarized in Fig. 4. The high- $V_{p}$ body with a slightly high $V_{p} / V_{s}(1.75 \sim 1.8)$ imaged on the hanging wall is con-

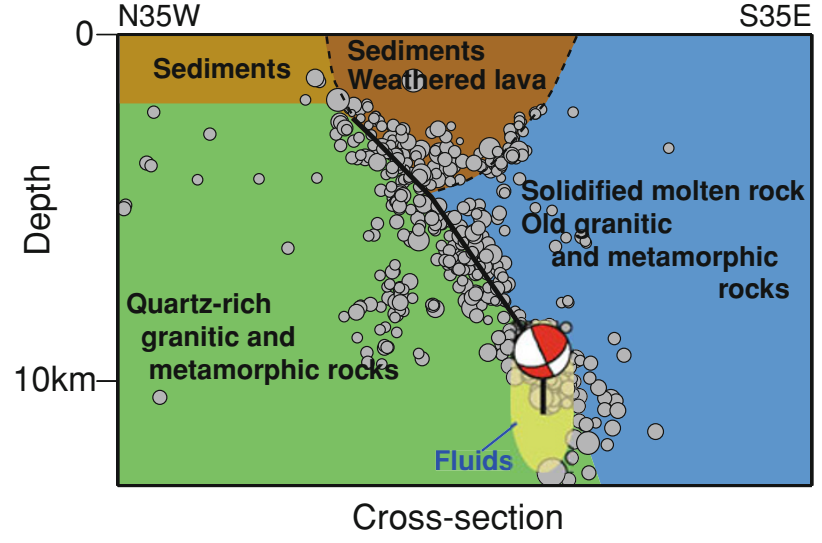

Fig. 4. Schematic image of the major heterogeneous structure in the $\mathrm{NE}$ areas of the mainshock hypocenter with the relocated aftershocks (gray circles scaled to earthquake magnitude) along the cross-sections of $Y=0,3,6$, and $9 \mathrm{~km}$. The solid line denotes the fault planes estimated from the aftershock distributions for the mainshock. Broken lines indicate the estimated faults. The moment tensor solution for the mainshock (NIED) is shown by lower backward projection.

sidered to be solidified molten rock (dike swarm) and old granitic and metamorphic rocks ( $\sim 200 \mathrm{Ma})$, which are exposed at the top of the hanging wall (GSJ, 2005). Since these granitic and metamorphic rocks are older than the extension of the Japan Sea, it is probable that they were formed before the extension. We propose that molten rock intruded into the southeastern region of the hanging wall during the extension stage (Shimazu et al., 1990). Since geological fault $F_{b}$ coincides with the shallow velocity boundary dipping northwestward $(Y=+3 \mathrm{~km}$; Fig. 2), it appears that the northern margin of the high- $V_{p}$ body in the hanging wall is roughly confined by this fault.

The low- $V_{p}$ body in the footwall has high $V_{p} / V_{s}$ values (>1.9) at shallow depths and low $V_{p} / V_{s}$ values $(1.6 \sim 1.7)$ at depths greater than $3 \mathrm{~km}$. The shallow high- $V_{p} / V_{s}$ bodies with significantly low $V_{p}$ (less than $5.0 \mathrm{~km} / \mathrm{s}$ ) correspond to the sediments that have piled over the half grabens formed by crustal stretching at the time of expansion of the Japan Sea (Fig. 4). Since the thickness of the sediments is less than approximately $3 \mathrm{~km}$, the extent of the crustal stretching is considered to be less significant compared with the Niigata region (e.g., Japan National Oil Corp., 1991; Kato et al., 2006). This result is consistent with the geological observation that the extent of rifting in the Noto Peninsula is small (Okamura, 2007). Conversely, it is possible that deep low- $V_{p} / V_{s}$ bodies in the footwall correspond to old quartz-rich granitic and metamorphic rocks, as laboratory experiments have demonstrated that quartz has a low $V_{p} / V_{s}$ value (e.g., Carmichael, 1982). However, this interpretation of the crustal composition of the footwall is not unique, and extensive additional research is necessary.

Geological studies show that the crustal shortening that began in the late Miocene (e.g., Itoh and Nagasaki, 1996) has continued to the present and has led to the reactivation of a fault that formed as a normal fault under an extensional stress field (e.g., Okamura et al., 1995). Therefore, a likely explanation for the Noto Hanto earthquake involves reactivation of a normal fault as a reverse fault in terms of in- 
(a)

(b)

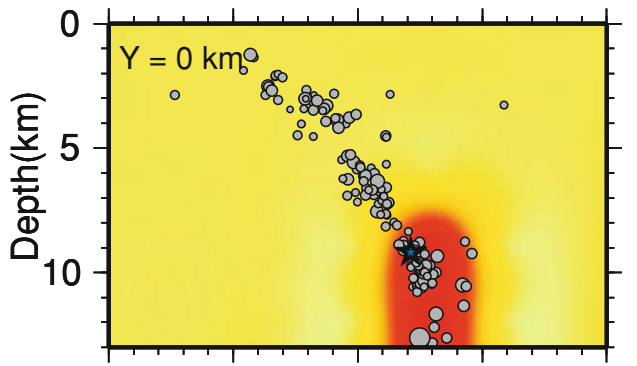

(c)
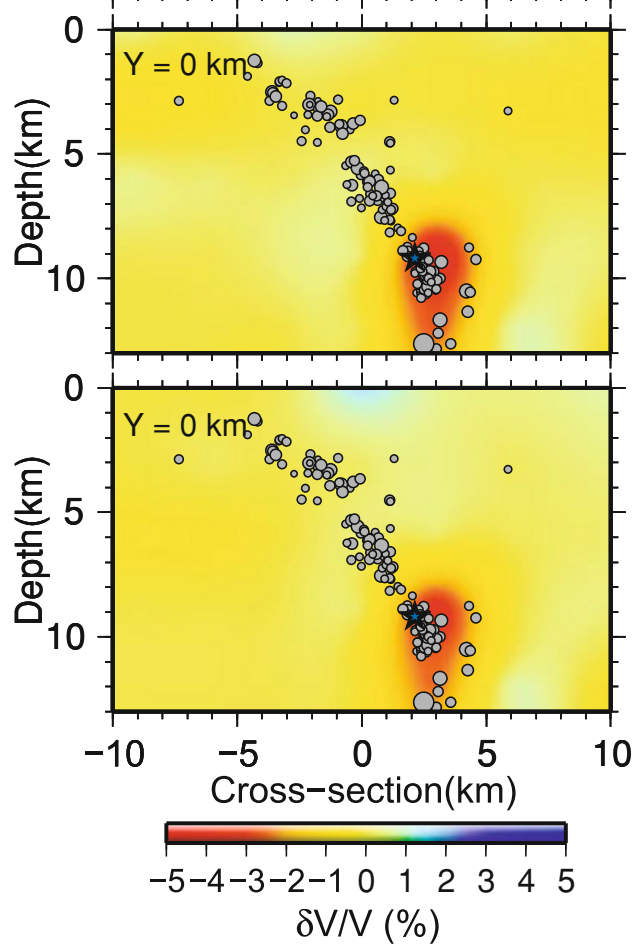

Fig. 5. Results of a sensitivity test (spike test) with a low-velocity body near and beneath the mainshock hypocenter along the cross-section of $Y=0 \mathrm{~km}$. (a) The input anomaly, (b) The test result of $V_{p}$, (c) The test result of $V_{s}$. A blue star denotes the mainshock hypocenter.

version tectonics (Nakamura, 1992). Tomographic images associated with the inverted normal fault have also been found in the source region of the 2004 mid-Niigata Prefecture Earthquake in the similar tectonic zone along the Japan Sea coast (e.g., Kato et al., 2006).

The velocity contrast between the hanging wall and the footwall extends from the SW to the NE in the source region. Although previous studies did not find any active faults inland in this region, the results of our study suggest that a major structural boundary with a NE-SW direction is situated at depths exceeding $3 \mathrm{~km}$ in the source region (Fig. 3). It is worth noting that trends in the velocity boundary are roughly parallel to the spreading axes of the Japan Sea.

As shown in Fig. 2, both the mainshock hypocenter and the vertical alignment of aftershocks beneath it are located in the low- $V_{p}$ zones where the low $V_{p} / V_{s}$ values were imaged. In order to assess the reliability of the model resolutions for these anomalies, we also conducted a spike test. Velocity anomalies of $-5 \%$ were assigned to a grid node near and beneath the mainshock hypocenter (Fig. 5(a), $X=3 \mathrm{~km}, Z=9$ and $12 \mathrm{~km}$ along the cross-section of
$Y=0 \mathrm{~km})$. The calculation of the synthetic travel-time and the inversion method were the same as those employed for the checkerboard model resolution test. The results shown in Figs. 5(b) and (c) indicate that the assumed velocity anomalies for $V_{p}$ and $V_{s}$ near the mainshock hypocenter were well recovered, although the recovery of $V_{s}$ was weaker than that of $V_{p}$. Based on these results, we consider that the presence of low-velocity anomalies near the mainshock hypocenter is reliable.

According to Takei (2002), the relatively low $V_{p} / V_{s}$ and low $V_{p}$ can be explained by the presence of water-filled pores with high aspect ratios. Furthermore, the detection of a conductive layer beneath the mainshock hypocenter by a magnetotelluric survey (MT) conducted after the occurrence of the mainshock (Yoshimura et al., 2008) supports the interpretation of the presence of water. Interestingly, a similar low-velocity zone with high conductivity was also observed near the hypocenter of the 2004 mid-Niigata Prefecture Earthquake (Uyeshima et al., 2005; Kato et al., 2006; Okada et al., 2006). It has been postulated that increased pore fluid pressure can potentially initiate a mainshock rupture. The initiated rupture is likely to have propagated through the structural boundary between the lowand high- $V_{p}$ bodies due to the relative mechanical weakness within the fault zone (Fig. 4). In fact, the fault plane of the mainshock is unfavorably oriented (Sibson, 1990) because the dip angle of the thrust fault is approximately $55^{\circ}$ from the maximum compressional axis, which is approximately horizontal. Consequently, a high pore fluid pressure or low frictional coefficient would be required within the fault zone (e.g., clay minerals) to reactivate the inverted normal fault. Unfavorably oriented faults were also observed in an aftershock sequence of the 2004 mid-Niigata Prefecture Earthquake (Kato et al., 2006; Sibson, 2007). It should be noted that the crustal stretching and shortening that has occurred along the Japan coastline has created complex structures, including weak high-dip angle faults, almost vertical faults, and low-velocity zones, all of which could affect the seismic activities around both the Noto Peninsula and the Niigata region.

Our analysis of the velocity structure (Fig. 2) revealed a varied seismic structure along the fault strike, particularly near the cross-section where $Y=+9 \mathrm{~km}$, or $+12 \mathrm{~km}$. Future research will be directed at the seismic structure along the fault strike using additional data sets to improve the imaging. We will also investigate the relationship between the heterogeneous velocity structure and the source process associated with the mainshock rupture, specifically, the distributions of coseismic or postseismic slip, stress-drops, or high-frequency energy radiation.

\section{Conclusions}

We have elucidated the velocity structure and accurate aftershock distributions of the 2007 Noto Hanto Earthquake by inverting the arrival times from 917 aftershocks observed by the dense seismic network deployed immediately after the mainshock. It appears that the $P$-wave velocity $\left(V_{p}\right)$ of the hanging wall in the SE is higher than those in the footwall at the NW and that the high- $V_{p}$ body of the hanging wall has a slightly higher $V_{p} / V_{s}$ ratio. In contrast, the 
low- $V_{p}$ body in the footwall appears to have a low $V_{p} / V_{s}$ ratio at depths greater than $3 \mathrm{~km}$. Aftershocks associated with the mainshock fault are distributed roughly along this velocity boundary between the hanging wall and footwall. Near-surface thin layers with significantly low $V_{p}$ and high $V_{p} / V_{s}$ are imaged northwestward from the mainshock epicenter. This thin layer corresponds to the sediments that have piled over the half grabens formed by crustal stretching in the opening of the Japan Sea. A likely explanation is that the mainshock fault plane was reactivated as a reverse fault in terms of the inversion tectonics due to the crustal shortening which initiated in the late Miocene. Both the mainshock hypocenter and the vertical alignment of aftershocks beneath it are located in the low $-V_{p}$ zone with highconductivity, which shows a potential presence of waterfilled pores.

Acknowledgments. We are grateful to $\mathrm{H}$. Zhang for use of the tomoDD code. We also thank Masaru Kobayashi, Toshio Haneda, Izumi Ogino, Shigeru Watanebe, Mamoru Saka, Koji Miyakawa, Atsushi Watanabe, Reiko Miura, Katsumi Miura, and Kiyoko Tagami for data acquisition and picking of first arrival times. We thank the Japanese University Group of the Joint Seismic Observations at NKTZ, the National Research Institute for Earth Science and Disaster Prevention, Japan Meteorological Agency, Kyoto University for allowing us to use the waveform data collected at each online station. We are grateful to Y. Okamura and A. Amato for their constructive comments and helpful suggestions, which led to substantial improvement in the original manuscript. We thank H. Sato for his useful comments. Most of the figures were created using GMT (Wessel and Smith, 1995). This research was partially supported by the Ministry of Education, Science, Sports and Culture (MEXT), Grant-in-Aid for Special Purposes, 19900001, 2007, and the Special Coordination Funds for the Promotion of Science and Technology (MEXT) under the title of an urgent research for the 2007 Noto Hanto Earthquake. The work is conducted as a part of the 2nd new program of research and observation for earthquake prediction (2004 to 2008).

\section{References}

Carmichael, R. S., Handbook of physical properties of rocks, edited by R. S. Carmichael, CRC Press, 1982.

Chiarabba, C. and A. Amato, $V_{p}$ and $V_{p} / V_{s}$ images in the Mw 6.0 Colfiorito fault region (central Italy): A contribution to the understanding of seismotectonic and seismogenic processes, J. Geophys. Res., 108(B5), 2248, doi:10.1029/2001JB001665, 2003.

Geological Survey of Japan (GSJ), AIST, 1:200,000 seamless digital geological map of Japan, 2005.

Hirata, N. and M. Matsu'ura, Maximum-likelihood estimation of hypocenter with origin time eliminated using nonlinear inversion technique, Phys. Earth Planet. Inter., 47, 50-61, 1987.

Hirata, N., H. Sato, S. Sakai, A. Kato, and E. Kurashimo, Fault system of the 2004 Mid Niigata Prefecture Earthquake and its aftershocks, Landslides, 2, 153-157, 2005.

Itoh, Y. and Y. Nagasaki, Crustal shortening of southwest Japan in the late Miocene, The Island Arc, 5, 337-353, 1996.

Japan National Oil Corp., Research report on the pilot drilling at "HigashiKubiki" for prospecting petroleum and natural gas in Japan, 1991 (in Japanese).

Kano, K., T. Yoshikawa, Y. Yanagisawa, K. Ogasawara, and T. Danhara, An unconformity in the early Miocene syn-rifting succession, northern Noto Peninsula, Japan: Evidence for short-term uplifting precedent to the rapid opening of the Japan Sea, The Island Arc, 11, 170-184, 2002.

Katagawa, H., M. Hamada, S. Yoshida, H. Kadosawa, A. Mitsuhashi, Y. Kono, and Y. Kinugasa, Geological development of the west sea area of the Noto Peninsula district in the Neogene Tertiary to Quaternary, central Japan, J. Geogr., 114, 791-810, 2005.

Kato, A., S. Sakai, N. Hirata, E. Kurashimo, T. Iidaka, T. Iwasaki, and T.
Kanazawa, Imaging the seismic structure and stress field in the source region of the 2004 mid-Niigata prefecture earthquake: Structural zones of weakness and seismogenic stress concentration by ductile flow, $J$. Geophys. Res., 111, B08308, doi:10.1029/2005JB004016, 2006.

Mikumo, T., H. Wada, and M. Koizumi, Seismotectonics of the Hida region, central Honshu, Japan, Tectonophysics, 147, 95-119, 1988.

Nakamura, K., Inversion tectonics and its structural expression, J. Tectonic Res. Group Jpn., 38, 3-45, 1992 (in Japanese with English abstract).

Okada, T., T. Yaginuma, N. Umino, T. Matsuzawa, A. Hasegawa, H. Zhang, and C. Thurber, Detailed imaging of the fault planes of the 2004 Niigata-Chuetsu, central Japan, earthquake sequence by doubledifference tomography, Earth Planet. Sci. Lett., 244, 32-43, 2006.

Okamura, Y., Tectonic History of the Noto Peninsula and its relation to the 2007 Noto Peninsula Earthquake, Japan Geoscience Union Meeting 2007, Z255-P055, 2007.

Okamura, Y., M. Watanabe, R. Morijiri, and M. Satoh, Rifting and basin inversion in the eastern margin of the Japan Sea, The Island Arc, 4, 166$181,1995$.

Otofuji, Y., T. Matsuda, and S. Nohda, Paleomagnetic evidence for the Miocene counter clockwise rotation of northeast Japan: Rifting processes of the Japan arc, Earth Planet. Sci. Lett., 75, 265-277, 1985.

Sakai, S., A. Kato, T. Iidaka, T. Iwasaki, E. Kurashimo, T. Igarashi, N. Hirata, T. Kanazawa, and the group for the joint aftershock observation of the 2007 Noto Hanto Earthquake, Highly-resolved distribution of aftershocks of the 2007 Noto Hanto Earthquake by a dense seismic observation, Earth Planets Space, 60, this issue, 83-88, 2008.

Schaff, P. D., G. H. R. Bokelmann, W. L. Ellsworth, E. Zanzerkia, F. Waldhauser, and G. C. Beroza, Optimizing Correlation Techniques for Improved Earthquake Location, Bull. Seismol. Soc. Am., 94, 705-721, 2004.

Shimazu, M., S. Yoon, and M. Takeishi, Tectonics and volcanism in the Sado-Pohang Belt from 20 to $14 \mathrm{Ma}$ and opening of the Yamato Basin of the Japan Sea, Tectonophysics, 181, 321-330, 1990.

Sibson, R. H., Rupture nucleation on unfavorably faults, Bull. Seismol. Soc. Am., 80, 1580-1604, 1990.

Sibson, R. H., An episode of fault-valve behaviour during compressional inversion?-The 2004 MJ6.8 Mid-Niigata Prefecture, Japan, earthquake sequence, Earth Planet. Sci. Lett., 257, 188-199, 2007.

Takei, Y., Effect of pore geometry on $V_{p} / V_{s}$ : From equilibrium geometry to crack, J. Geophys. Res., 107(B2), 10.1029/2001JB000522, 2002.

The Japanese University Group of the Joint Seismic Observations at NKTZ, The Japanese University Joint Seismic Observations at the Niigaka-Kobe Tectonic Zone, Bull. Earthq. Res. Inst. Univ. Tokyo, 80, 133-147, 2005.

Townend, J. and M. D. Zoback, Stress, strain, and mountain building in central Japan, J. Geophys. Res., 111, B03411, doi:10.1029/ 2005JB003759, 2006

Uyeshima, M., Y. Ogawa, Y. Honkura, S. Koyama, N. Ujihara, T. Mogi, Y. Yamaya, M. Harada, S. Yamaguchi, I. Shiozaki, T. Noguchi, Y. Kuwaba, Y. Tanaka, Y. Mochido, N. Manabe, M. Nishihara, M. Saka, and M. Serizawa, Resistivity imaging across the source region of the 2004 Mid-Niigata Prefecture earthquake (M6.8), central Japan, Earth Planets Space, 57, 441-446, 2005.

Wessel, P. and W. H. F. Smith, New version of the generic mapping tools released, EOS Trans. AGU, 76, 329, 1995.

Yamada, T., K. Mochizuki, M. Shinohara, T. Kanazawa, A. Kuwano, K. Nakahigashi, R. Hino, K. Uehira, T. Yagi, N. Takeda, and S. Hashimoto, Aftershock observation of the Noto Hanto earthquake in 2007 using ocean bottom seismometers, Earth Planets Space, 2007 (submitted).

Yoshimura, R., N. Oshiman, M. Uyeshima, Y. Ogawa, M. Mishina, H. Toh, S. Sakanaka, H. Ichihara, I. Shiozaki, T. Ogawa, T. Miura, S. Koyama, Y. Fujita, K. Nishimura, Y. Takagi, M. Imai, R. Honda, S. Yabe, S. Nagaoka, M. Tada, and T. Mogi, Magnetotelluric observations around the focal region of the 2007 Noto Hanto Earthquake $\left(M_{\mathrm{j}} 6.9\right)$, Central Japan, Earth Planets Space, 60, this issue, 117-122, 2008.

Zhang, H. and C. H. Thurber, Double-difference tomography: The method and its application to the Hayward fault, California, Bull. Seismol. Soc. Am., 93, 1875-1889, 2003.

A. Kato (e-mail: akato@eri.u-tokyo.ac.jp), S. Sakai, T. Iidaka, T Iwasaki, E. Kurashimo, T. Igarashi, N. Hirata, T. Kanazawa, and Group for the aftershock observations of the 2007 Noto Hanto Earthquake 